\title{
Teoría de regímenes internacionales: el caso del recurso agua en el régimen ambiental México-Estados Unidos*
}

\section{Theory of international regimes: The case of water resources in the Mexico-United States environmental regime}

\author{
Mauricio Lascurain** \\ Academia de Estudios Internacionales, El Colegio de Veracruz, \\ México. \\ Recibido: 31 de julio de 2017. Aprobado: 23 de agosto de 2018.
}

\begin{abstract}
Resumen
Desde una perspectiva teórica de los regímenes internacionales, el estudio del régimen ambiental México-Estados Unidos permite visualizar su funcionamiento y evaluar si este ha cumplido con los objetivos de su creación. En este sentido, los enfoques neorrealistas y neoliberales ofrecen diferentes interpretaciones del fenómeno de cooperación internacional, así como también de su probabilidad y factibilidad de ocurrencia. En el contexto de las relaciones bilaterales entre México y Estados Unidos, los problemas comunes en materia ambiental en la frontera han originado la formación de un régimen, con la finalidad de solucionar los problemas de contaminación, degradación y deterioro ambiental que se presentan en la zona fronteriza. Sin embargo, Estados Unidos se presenta como el país más poderoso y hegemónico, por lo que México suele verse menos beneficiado de las decisiones tomadas dentro del régimen. El presente artículo pretende identificar la operatividad del régimen ambiental México-Estados Unidos, específicamente para el caso de la problemática hídrica en la frontera, bajo los principios básicos de la teoría de regímenes internacionales con la finalidad de entender si los miembros del régimen y sus políticas públicas constituyen un sistema de niveles múltiples de gobernanza.
\end{abstract}

* $\quad$ Este artículo se realizó sin ningún financiamiento específico y es parte de los trabajos que se realizan regularmente en la Academia de Estudios Internacionales de El Colegio de Veracruz.

** Doctor en el Programa de Nueva Economía Mundial, Universidad Autónoma de Madrid; maestro en Relaciones Internacionales, Universidad de Essex del Reino Unido; licenciado en Comercio Exterior y Aduanas, Universidad Iberoamericana de Puebla. Profesor-investigador, El Colegio de Veracruz, adscrito a la Academia de Estudios Internacionales. El Colegio de Veracruz. Carrillo Puerto $\mathrm{N}^{\circ}$ 26, Colonia Centro, C.P. 91000, Xalapa Veracruz, México. Correo electrónico: maulascurain @ gmail.com 
Palabras clave: teoría de regímenes internacionales, régimen ambiental, relación bilateral México-Estados Unidos.

\begin{abstract}
From the theoretical perspective of international regimes, the study of the US-Mexico environmental regime allows us to visualize how it works and assess whether it has fulfilled its intended objectives. In this sense, neorealist and neoliberal approaches offer different interpretations for the phenomenon of international cooperation, as well as the probability and feasibility of its success. In the context of bilateral relations between Mexico and the United States, the environmental problems affecting both countries in the border zone have led to the formation of a regime that aims to resolve issues of pollution, degradation and environmental deterioration. Nevertheless, given how the United States positions itself as the more powerful and dominant country, Mexico tends to benefit less from the decisions taken within this regime. This article aims to identify the workings of the US-Mexico environmental regime, specifically with respect to water issues in the border zone. In this regard it takes into account the basic principles of the theory of international regimes in order to understand whether the members of the regime and their public policies, constitute a system of multiple levels of governance.
\end{abstract}

Keywords: theory of international regimes, environmental regime, Mexico-United States bilateral relationship.

\title{
Introducción
}

Las fronteras entre los países son siempre puntos de contacto y cooperación, y la forma de entender esas interacciones es analizando cómo los gobiernos y sus comunidades trabajan para combatir los problemas económicos, sociales, políticos y ambientales. No obstante, por su misma naturaleza, las fronteras también son fuente de tensiones y conflictos. Dentro del debate de las relaciones internacionales, respecto de la interacción entre dos naciones en el sistema internacional para resolver un problema común, necesariamente se hace referencia a las teorías neorrealista-neoliberal institucionalista. Cada una de estas perspectivas teóricas busca entender cómo el contexto anárquico del sistema internacional inhibe la acción conjunta entre los Estados, los cuales comparten intereses comunes, permitiendo así que los Estados superen estas separaciones y logren avances en la cooperación. 
En este sentido, los neorrealistas enfatizan que la coordinación internacional es posible. Sin embargo, sugieren que es difícil de alcanzar y aún más difícil de mantener. Para los neorrealistas, el término gobernanza implica que los gobiernos son los actores cruciales. Por otro lado, la visión neoliberal asume el término de gobernanza como los procesos de elaboración de reglas que se dan entre un conjunto de actores dispersos, a fin de resolver un problema en común, por lo que la cooperación es viable y sostenible en el tiempo. Así, los gobiernos pueden unirse para formar un régimen internacional, con la finalidad de mitigar o resolver alguna problemática, y de acuerdo con la teoría de regímenes internacionales, el país hegemónico tiene el poder de manipular a los miembros del régimen e imponer sus decisiones sobre el resto de miembros, o bien, serán capaces de cooperar de forma conjunta y equitativa.

Bajo este escenario, los problemas comunes en materia ambiental en la franja fronteriza México-Estados Unidos han originado la formación de un régimen ambiental entre ambos países, con la finalidad de solucionarlos. Dentro del amplio abanico de problemas ambientales, sin duda el tratamiento y el uso del agua es uno de los principales, ya que desempeña un papel único en la economía tradicional de los habitantes de la frontera, además que la disponibilidad de un suministro adecuado y utilizable otorga sostén a la economía de la región. Pese a que entre ambos países existe una gran disparidad en el crecimiento poblacional, los procesos de industrialización y la degradación ambiental se pueden considerar como una zona de cooperación más de estilo neoliberal que neorrealista.

México y Estados Unidos comparten un territorio de $3.180 \mathrm{~km}$, y las comunidades establecidas desde la Costa del Pacífico hasta el Golfo de México dependen de los ríos Colorado y Bravo para su desarrollo. El recurso agua de estas cuencas es usado para el consumo, la irrigación de siembras, el soporte de vida silvestre y la recreación, lo que convierte al agua en un elemento fundamental para el sustento en toda la frontera. De este modo, los asuntos ambientales se presentan como una de las prioridades en las agendas de ambos gobiernos, para intentar mitigar el impacto de las actividades humanas a lo largo de la región fronteriza México-Estados Unidos, ya que el deterioro ambiental en esta zona ha comprometido la distribución de los recursos acuíferos y el uso del agua limpia.

Como resultado, varias instituciones gubernamentales en los tres órdenes de gobierno (federal, estatal y municipal), así como miembros activos de la sociedad civil de ambos países, han surgido para promover acciones comunes que atiendan las amenazas ambientales. Desde una perspectiva neoliberal, estas surgen como el resultado de la creciente necesidad de coordinar políticas creadas por la interdependencia de las instituciones federales, subnacionales y la sociedad civil de ambos países. Por otro lado, bajo la perspectiva neorrealista, la difusión del poder, creada por el surgimiento de estas organizaciones 
internacionales, disminuye paulatinamente la habilidad de ambos países y respectivas agencias para establecer el orden (Keohane, 1989).

El objetivo del presente trabajo consiste en identificar la operatividad del régimen ambiental México-Estados Unidos, particularmente en el caso del recurso agua, bajo los principios básicos de la teoría de regímenes internacionales (Krasner, 1983), con la finalidad de entender si los miembros del régimen y sus políticas públicas constituyen un sistema de niveles múltiples de gobernanza. Para abordar estos temas, el artículo se ha dividido en cinco secciones. La primera aborda los conceptos básicos de la teoría de regímenes internacionales y su adaptación en los temas medioambientales. La segunda parte describe el funcionamiento de un sistema de gobernanza y su aplicación en la operatividad del régimen ambiental México-Estados Unidos. En tercer lugar, se desarrolla la efectividad del régimen y los alcances de este para mitigar el problema ambiental en la región fronteriza. Cuarto, se ejemplifica la actividad del régimen a través del estudio de los problemas del agua que enfrenta la región, en donde se identifican al menos cuatro factores fundamentales del bajo desempeño del régimen: el abastecimiento equitativo del agua, la escasez actual y futura del recurso, la contaminación de las aguas y el trato de las aguas freáticas. Por último, en la sección de conclusiones se entregan algunas consideraciones finales.

\section{Teorizando los regímenes internacionales}

En la disciplina de las relaciones internacionales, un régimen puede ser descrito como cualquier forma o regla. A mediados del siglo XX, varios autores definieron lo que ahora conocemos como régimen internacional bajo el concepto tradicional de sistema internacional. De acuerdo con D. Puchala y R. Hopkins (1983), la conceptualización de régimen es similar a lo que solía ser utilizado como sistema, es decir, sus orígenes, su estructura, su impacto sobre los participantes, su duración y su transformación. Así, S. Hoffmann (1965) definió los sistemas internacionales como un modelo de relaciones entre las unidades básicas de la política mundial, que bajo un esquema analítico adquieren una forma de organización de la información amplia y compleja. Por su parte, M. Kaplan (1964) sostiene que los sistemas son un conjunto de variables relacionadas entre sí, pero diferentes a su ambiente natural, en donde ciertas regularidades de comportamiento caracterizan las relaciones de las variables internas con las externas.

Es a finales de la década de los setenta y principios de los ochenta que algunos autores, entre ellos Ernest B. Hass (1983), se cuestionan la necesidad de modificar los conceptos de sistemas, estructuras y bienes públicos. En esta actualización conceptual se sostiene que el sistema internacional, "como conjunto de leyes estructurales, es inapropiado y que estos 
pueden ser vistos como el resultado del comportamiento modelado de un actor" (Hass, 1983, p. 58). De este modo, el surgimiento del concepto de régimen ha proporcionado el paradigma dominante para las discusiones mundiales sobre cooperación internacional. En los últimos 35 años se ha generado un intenso debate sobre cuál debería ser el significado apropiado para definir un régimen internacional. ${ }^{1}$ Una de las definiciones de régimen internacional más aceptadas alrededor del mundo es la propuesta por Stephen Krasner, quien propone que un "régimen internacional es un conjunto implícito o explícito de principios, normas, reglas y procedimientos de toma de decisiones, alrededor de los cuales las expectativas de los actores convergen en un área de las relaciones internacionales" (1983, p. 2). De la anterior definición se desprenden tres elementos clave del régimen internacional. Los principios, que son creencias de hechos, causalidades y rectitud. Las normas, que son interpretadas como estándares de conducta definidas en términos de derechos y obligaciones. Finalmente, los procesos de toma de decisiones, entendidos como las prácticas prevalecientes para hacer implementar la elección colectiva (Krasner, 1983).

A pesar de que la anterior definición de Krasner ha servido como plataforma de análisis de estudio de los regímenes internacionales, en la década de 1990, los autores M. A. Levy, O. Young y M. Zürn (1994) propusieron la adecuación de la definición a fin de que esta abarcara prácticas sociales reconocidas en un ámbito internacional. En este sentido, los regímenes internacionales podrían ser vistos como "instituciones sociales que consisten en acuerdos sobre principios, normas, reglas, procedimientos y programas que gobiernan las interacciones de actores en áreas específicas" (Levy et al., 1994, p. 13).

Una diferencia sustancial entre la definición de Krasner y Levy et al. es que la de estos últimos utiliza la palabra gobernar para referirse al término gobernanza. En esta misma línea, Oran Young sostiene que la gobernanza "surge como un asunto de preocupación pública donde los miembros de un grupo social descubren que son interdependientes" (1997, p. 2), es decir, que las acciones individuales tienen un impacto en el bienestar de los demás. Más aún, la gobernanza involucra el establecimiento y operación de instituciones sociales, como por ejemplo las reglas, los procesos de toma de decisiones y las actividades pragmáticas que permiten definir las acciones sociales y guiar las interacciones de aquellos que participan en ellas.

La anterior definición permite la inclusión de casi cualquier asunto internacional. Actualmente existen regímenes internacionales en asuntos monetarios (como lo fue Bretton Woods), otros que tienen que ver con el comercio de bienes y servicios (Organización

$1 \quad$ Para un mayor análisis sobre dicho debate conceptual, ver Hasenclever, Mayer y Rittberger (1997); Conca (1996); Hass (1983); Krasner (1983); Levy, Young y Zürn (1994); Vogler (1995); Young (1980) у Haggard y Simmons (1987). 
Mundial de Comercio), y algunos que se enfocan a la ética de las relaciones internacionales (Declaración Universal de los Derechos Humanos o el Pacto Internacional sobre Derechos Civiles y Políticos). ${ }^{2}$ Por lo tanto, es posible distinguir que los regímenes internacionales son medidas más especializadas concernientes a actividades bien definidas, recursos o áreas geográficas y que frecuentemente involucran a miembros de la sociedad nacional e internacional, quienes a través de un proceso de coordinación política resuelven conflictos específicos en un área de interés común.

Bajo esta perspectiva, ¿cómo funciona y en qué consiste un régimen internacional en materia ambiental? De acuerdo con Young, los regímenes medioambientales "son acuerdos institucionales que gobiernan el uso humano de los recursos naturales y los servicios ambientales; y que pueden ser tanto, locales, regionales e internacionales" (1989, p. 8). Este tipo de régimen se fundamenta en la multiplicidad y diversidad en el manejo de los recursos naturales, en donde coexisten actores que poseen distintas capacidades con respecto a un recurso dado y de cómo gestionarlo. El reto es crear una situación en la cual la recompensa sea mayor por colaborar en el tratamiento del recurso que competir por él. Asimismo, los regímenes ambientales se fundan en el concepto de bien común, es decir, en la confianza de que es posible identificar un curso de acción que armonice diferentes intereses. Además, este tipo de régimen se refiere al manejo como un proceso susceptible de revisión permanente y mejoramiento, más que a la estricta aplicación de un conjunto de reglas establecidas.

Por otro lado, los regímenes ambientales, al igual que otros regímenes internacionales, son considerados como instituciones sociales (Young, 1989; Keohane, 1989), los cuales se encuentran en constante actualización debido a que se desarrollan y evolucionan con el tiempo. De acuerdo con C. Harper (1996), para poder entender y atender los problemas ambientales en determinadas regiones o a nivel internacional, los regímenes internacionales deben evolucionar constantemente, con la finalidad de satisfacer las nuevas necesidades generadas dentro del mismo régimen, tomando en consideración las demandas de los nuevos miembros o actores, así como los cambios constantes ocurridos dentro de la agenda política internacional. En este sentido, ¿cómo opera el régimen ambiental México-Estados Unidos? A continuación, se describen sus principales características y elementos operacionales.

2 Existen diferentes regímenes en casi todos los temas que abordan las relaciones internacionales. 


\section{Operación del régimen ambiental México-Estados Unidos como sistema de gobernanza}

Para entender la operatividad del régimen ambiental México-Estados Unidos, es necesario conocer si las respectivas instituciones que operan dentro del régimen y sus políticas públicas constituyen un sistema de niveles múltiples de gobernanza, así como identificar los principales problemas que permanecen presentes en la agenda del régimen. Para ello es preciso comprender si existen otros actores importantes, aparte de las instituciones nacionales y supranacionales, tales como la Comisión Internacional de Límites y Aguas (CILA), ${ }^{3}$ la Secretaría de Medio Ambiente y Recursos Naturales de México (Semarnat) y la U.S. Environmental Protection Agency (EPA), que de una forma u otra determinan las políticas y programas que son necesarios en la región fronteriza. Estos actores, normalmente ubicados en los niveles altos-medios de la toma de decisiones, ponen en práctica nuevas alianzas de cooperación transfronteriza, en donde el desarrollo regional es un elemento importante de interacción dentro del contexto político multilateral y de integración económica.

Es importante resaltar que cada régimen ambiental internacional es único. En este sentido, el régimen ambiental México-Estados Unidos tiene características particulares que lo distinguen del resto de los regímenes de alrededor del mundo. Para entender la forma en que este trabaja, se necesita analizar los diferentes niveles en los que las políticas públicas ambientales son implementadas. Así, una característica importante del régimen es la activa combinación de instituciones binacionales, nacionales, estatales y locales dentro de la franja fronteriza. De esta manera, es posible presenciar diferentes formas de niveles múltiples de gobernanza que se caracterizan por tener distintos actores con funciones similares, coordinándose entre sí para lograr objetivos comunes.

Usualmente, el concepto de gobernanza puede ser entendido como el establecimiento, operación e implementación de un conjunto de reglas de conducta que definen prácticas, asignan roles, a través de los cuales se gestionan los asuntos públicos de manera transparente, participativa, inclusiva y receptiva (Unesco, 2017) ${ }^{4}$. De manera similar, N. Veggeland (2000) define la gobernanza como una forma de gobierno en la que grupos e individuos de diferentes instituciones, organizaciones, empresas y niveles de trabajo en cadenas, toman decisiones sobre las bases del diálogo, la negociación y la cooperación. Por lo tanto, gobernanza significa un proceso interactivo de toma de decisiones a través de un constante e intenso debate de ideas.

3 La CILA es un organismo internacional creado en 1889 por Estados Unidos y México, con el fin de aplicar los tratados internacionales sobre límites y aguas entre estas dos naciones.

4 En un sentido amplio, la gobernanza se refiere a la cultura y el entorno institucional en el que los ciudadanos y las partes interesadas interactúan entre sí y participan en los asuntos públicos. 
De acuerdo con V. Kotow, S. Kux y E. Nikitina (1998), los regímenes ambientales internacionales son una buena ilustración de un sistema de gobernanza. En un régimen ambiental, los Estados signatarios traducen las obligaciones hacia programas de estructura nacional y llegan a una decisión sobre las responsabilidades de la implementación que recaen en los niveles regionales y locales. Posteriormente, los gobiernos locales y regionales desarrollan sus propios programas para satisfacer los estándares y objetivos nacionales. ${ }^{5}$

En la mayoría de los casos de implementación, se debe recurrir a diferentes y complejas formas de cooperación entre los tres niveles de acción con el objeto de encontrar resultados tangibles. Aun en países altamente centralizados como Francia o Suecia, las autoridades nacionales dependen de la cooperación de administraciones regionales y locales para obtener resultados efectivos y eficientes (Wurzel, Zito y Jordan, 2013). Sin embargo, la idea de este proceso de estratificación también contiene ciertas desventajas. Primero, el ámbito de los problemas ambientales normalmente no se concentra en una sola región, sino que trasciende a otras latitudes, por lo que requiere una coordinación al más alto nivel. En segundo lugar, existe el riesgo de caer en lo que Fritz Scharpf (1988) denominó como "la trampa de decisión conjunta". 6

Para L. Lebel et al. (2006), los sistemas de gobernanza no son competencia exclusiva del Estado a través del gobierno, sino que emergen de las interacciones de muchos actores, incluyendo el sector privado y organizaciones sin fines de lucro. Estos sistemas de gobernanza pueden institucionalizarse formalmente o expresarse mediante normas sutiles de interacción o incluso más indirectamente influyendo en las agendas y configurando los contextos en los que los actores impugnan las decisiones y determinan el acceso a los recursos. En este sentido, pueden localizarse en diferentes niveles de acción, como por ejemplo aquellos asuntos mundiales en los que la autoridad está siendo reubicada desde la arena estatal hacia arenas donde los actores subnacionales, trasnacionales e incluso algunas veces supranacionales desempeñan un papel significativo.

$5 \quad$ Kotow et al. (1998) también sugieren que las políticas públicas ambientales, nacionales e internacionales están envueltas en diversas capas y este proceso de difusión política puede ser entendido comparándolo con una muñeca babuska rusa. Por ejemplo, los acuerdos ambientales internacionales que tienen que ver con el régimen entre México y Estados Unidos forman el exterior (la muñeca contenedora); la legislación nacional, la parte intermedia y los programas regionales y locales representan las capas internas (las muñecas contenidas). Puede ser posible, aunque solo a posteriori, determinar si una alternativa de solución a un objetivo particular de protección ambiental puede alcanzarse de forma efectiva y eficiente en los ámbitos regional, nacional e internacional.

6 Alude a la idea de que las decisiones en condiciones de unanimidad tienden a favorecer a los que defienden el statu quo y a penalizar a los que quieren promover cambios. 
Existe evidencia empírica (Aguilar, 2014; Lebel et al., 2006; Stoker, 1998; Braczyk y Heindenreich, 2005; Saerbeck, Jörgensen y Jänicke, 2017) que afirma que las sociedades modernas son cada vez más complejas y divididas, debido a que normalmente estas se construyen de subsistemas socialmente diferenciados y con un campo de acción relativamente autónomo, como podría ser el caso de la región fronteriza entre México y Estados Unidos. En este sentido, los niveles múltiples de gobernanza también se refieren a la idea de multiplicidad y diversidad entre los actores, lo que permite pensar en el manejo de los asuntos internacionales, tal como el medio ambiente, no como una actividad interestatal, sino como un proceso de participación, negociación, interacción y cooperación entre grupos heterogéneos.

Esta clase de gobernanza dentro del régimen ambiental México-Estados Unidos puede ser entendida como el resultado de los esfuerzos hechos por más de 40 años, cuando ambos países estuvieron buscando mecanismos para mitigar los problemas ambientales en las áreas fronterizas. Pensando en las relaciones binacionales entre México y Estados Unidos, y en términos de niveles múltiples de gobernanza, esto refleja una actitud intelectual ideológicamente madura. La percepción de la forma en cómo el régimen maneja los problemas ambientales en esta región es un intento por dar un papel más activo a los actores que han estado comúnmente ignorados.

De acuerdo con Young (1997), la idea de la gobernanza surge como un asunto de preocupación pública cuando los miembros de la sociedad civil descubren que son interdependientes; es decir, la forma como cada miembro busca el bienestar de los demás. La interdependencia, a su vez, da lugar a conflictos cuando los esfuerzos de unos actores por cumplir sus objetivos interfieren o impiden los esfuerzos de otros por alcanzar sus propios fines.

El caso del régimen ambiental México-Estados Unidos tiene un alto grado de interdependencia, debido al hecho de que las dependencias ambientales de ambos países (Semarnat y EPA) funcionan como líderes de las acciones estatales, locales y de otros niveles de la sociedad. Esto quiere decir que los niveles más bajos dependen técnicamente y financieramente de la estructura gubernamental central. Sin embargo, de manera contradictoria, los niveles más altos dependen de los inferiores para un mejor conocimiento del problema y sus posibles alternativas de solución. ${ }^{7}$

Sería razonable pensar que el régimen ambiental México-Estados Unidos se propondría llevar a cabo sus programas tan simple y directamente como fuera posible, guardando

\footnotetext{
${ }^{7}$ Para Young (1997), entre más interdependencia exista entre los participantes de un régimen, más penetrantes y complejos llegan a ser los problemas de acción colectiva.
} 
distancia de la participación de otras dependencias federales, estatales y locales, así como de organizaciones no gubernamentales y de la comunidad en general. Sin embargo, estos sectores tienen cada vez mayor participación en los procesos de toma de decisión e implementación. Por ejemplo, en cuatro niveles distintos de gobierno (internacional, nacional, estatal-regional y local) es posible identificar dentro del régimen a cerca de 90 actores involucrados, como instituciones bilaterales, tales como la Comisión para la Cooperación Ambiental (CCA), la Comisión de Cooperación Ecológica Fronteriza (COCEF) o la CILA, instituciones nacionales como la Semarnat o la EPA, y los diferentes gobiernos municipales fronterizos y actores de la sociedad civil fronteriza, como Alianza Sierra Madre A.C., Pronatura A.C., The Nature Conservancy o Greenpeace. ${ }^{8}$

Por otro lado, es preciso señalar que para cuando fueron creados los programas y esfuerzos bilaterales como el Programa Frontera XXI México-Estados Unidos, ${ }^{9}$ de manera bilateral los gobiernos de Estados Unidos y México firmaron en 1993 el Acuerdo de Cooperación Ecológica Fronteriza (ACEF), que dio origen a la COCEF junto con el Banco de Desarrollo de América del Norte (BDAN), ${ }^{10}$ como parte del TLCAN. En ese entonces, el objetivo principal de ambos países era establecer un acuerdo comercial y de crecimiento económico para comenzar a incluir otros temas importantes, entre ellos los asuntos ambientales. Sin embargo, era cuestión de tiempo insertar aquellos niveles faltantes dentro de las agendas de México y Estados Unidos, debido a las presiones reales e inminentes de los sectores que originalmente estaban excluidos de la elaboración de las políticas públicas internas, así como de su implementación.

Lo que había parecido un proyecto simple, urgente y directo para salvar el medio ambiente y las aguas de la frontera entre México y Estados Unidos, involucrando la participación de la CILA y el Acuerdo de La Paz, ${ }^{11}$ finalmente sumó a un número mayor de diversos participantes e involucró una serie de decisiones mucho más amplias que fueron planeadas hace casi 35 años. Aunque ninguno de los participantes estuvo en desacuerdo con los principales objetivos ambientales del régimen, sí tuvieron diferentes perspectivas y sentidos

8 En la frontera interactúan seis estados mexicanos: Baja California, Sonora, Chihuahua, Coahuila, Nuevo León y Tamaulipas, y 39 municipios. De la parte estadounidense son cuatro estados: California, Nuevo México, Arizona y Texas, y 24 municipios.

9 El objetivo principal del programa consistió en promover el desarrollo sustentable, buscando un equilibrio entre los factores económicos y sociales con la protección del ambiente.

10 El BDAN y su institución hermana, la COCEF, fueron creados bajo los auspicios del TLCAN para atender problemas ecológicos en la región fronteriza entre México y Estados Unidos. Las dos instituciones operan de conformidad con el "Acuerdo entre el Gobierno de Estados Unidos Mexicanos y el Gobierno de los Estados Unidos de América sobre el Establecimiento de la Comisión de Cooperación Ecológica Fronteriza y el Banco de Desarrollo de América del Norte", que se firmó en noviembre de 1993.

11 Convenio entre México y Estados Unidos firmado en 1983, sobre Cooperación para la Protección y Mejoramiento del Medio Ambiente en la Zona Fronteriza. 
de urgencia, lo que hace más difícil para traducir un acuerdo esencial y a la vez amplio, en un proceso efectivo de implementación de políticas públicas.

En el entendido de que el régimen ha estado trabajando en esta clase de procedimientos, sería razonable pensar que las instituciones involucradas son interdependientes y suplementarias entre ellas; sin embargo, esta situación solo aplica en pocas ocasiones al momento de implementar políticas especiales. La mayoría de las veces los integrantes del régimen conducen programas y políticas manteniendo sus propias racionalidades y códigos de acción. De acuerdo con P. Berman (1980), la participación activa de actores importantes en diferentes categorías fortalece la solución de problemas durante la implementación, solo porque se asume que los participantes disímiles traen más información y más puntos de vista a considerar; tal diversidad podría aminorar serios problemas de pensamiento grupal, tendencias de manejo de alto nivel y falta de comunicación.

Al mismo tiempo, G. Downs y L. Mohr (1976) apoyan la idea de tener un gran número de participantes, en el entendido de que se pueden producir mejores resultados por medio de mayores consultas y consensos. No obstante, L. Pressman y A. Wildavsky (1973) sostienen que la mayoría de las dificultades están causadas, precisamente, por la multiplicidad de actores y por dependencias gubernamentales que compiten y que tienen responsabilidades que se traslapan, lo cual resulta ser la norma común en la mayoría de las áreas de servicio social.

En este sentido, las estructuras de niveles múltiples de gobernanza dentro de un régimen, como el de este estudio, afectan el papel que ejerce cada institución, así como también sus funciones específicas. Esto, sin duda es un hecho verdadero al momento de analizar las relaciones entre las funciones legales y políticas de la implementación. Por tanto, en la estructura del régimen ambiental México-Estados Unidos, con muchas y diferentes instituciones políticas y leyes, existen relaciones jerárquicamente orientadas; es decir, de forma constante la coordinación jerárquica y la desregulación sufren de problemas de eficiencia y legitimidad dentro de un contexto complejo y dinámico de formulación de políticas públicas. ${ }^{12}$

12 Es preciso considerar que cada institución (independientemente del lugar en el que está posicionada) tiene sus propias reglas y principios, pero, aún más importante, tiene su propia forma de abordar los problemas ambientales en el área. Toda esta variedad de formas y sentidos para atender los problemas ambientales, influye en definitiva en el proceso para implementar de manera efectiva y eficiente las diferentes políticas públicas ambientales que son requeridas en la frontera. Lo anterior no es solo el resultado de contar con estructuras de niveles múltiples de gobernanza, sino también de la alta complejidad de este proceso, lo que significaría que las diferentes formas de hacer política (policy-making) tendrían que interactuar estrechamente. 
Sin embargo, un tema fundamental en el funcionamiento del régimen en cuestión es sin duda el tratamiento del concepto de la soberanía de ambos Estados. Cuando México y Estados Unidos interactúan en una arena internacional, se han caracterizado por mantener la unidad (Peña, 2011; Gallagher, 2009). Cuando estos se confrontan por culpa de un lenguaje de gobernanza que ha evolucionado en un régimen, así como por las extrañas relaciones institucionales, difícilmente se puede dar una descripción adecuada en relación con las acciones de los Estados miembros.

Ahora bien, la participación dentro del régimen está integrada por numerosos agentes y dependencias de los Estados miembros y del mismo régimen, que siguen procedimientos múltiples y trayectorias formales e informales. Con tales formas de gobernanza sería una ficción conservar la idea de unidad soberana para cada país. El sistema de gobernanza es más bien llevado a cabo por medio de diversas instituciones y con el uso de muchas y variadas trayectorias de relaciones entre estas. Las instituciones trabajan de manera autónoma, pero a la vez entrelazadas; incluso si algunas de ellas tienen cierta clase de poder supremo en la toma de decisiones, son de igual forma dependientes de otras instituciones para postular iniciativas y generar resultados sustanciales (Peña, 2011).

Así, la idea clásica de soberanía podría entonces disolverse hacia estos patrones de cooperación múltiple y de combinación de instituciones, así como hacia la entrada de significativos grados de relativa autonomía para cada institución. La situación de escenarios compuestos de las instituciones de gobernanza crea una situación de negociaciones prolongadas y competencias entre las instituciones. Para B. Jessop (2000), cuando la soberanía del Estado es diluida, como podría ser el caso de la frontera entre México y Estados Unidos, el nivel de negociación y gobernanza interactiva se incrementa. ${ }^{13}$

Por lo tanto, es posible decir que existe un cambio en la soberanía cuando los Estados implementan un esquema de integración tanto político, económico o ambiental, creando así un sistema de niveles múltiples de gobernanza con tareas de gran alcance, es decir, enfocándose en áreas centrales de la sociedad.

De esta manera, dentro de la región fronteriza entre México y Estados Unidos, la esfera de responsabilidades y toma de decisiones está asegurada sobre las bases de un proceso de negociación entre autoridades regionales y estatales, y la soberanía toma la forma de un

13 De acuerdo con Veggeland (2000), esto sucede, primero, por el desarrollo de niveles múltiples de gobernanza y, segundo, a raíz del proceso de regionalización que se da en la frontera y la formación de regiones fronterizas entre ambos países y, en tercer lugar, en relación con los actores no estatales en el sistema. Además, sugiere también que la negociación de acuerdos no se da solo en el ámbito trasnacional, sino también, en un alto grado, dentro de los límites de los Estados nacionales. Por tanto, las negociaciones y la cooperación tienen lugar en un espacio multidimensional y con la presencia de muchos actores. 
contrato hecho entre diferentes partes. Esta forma de cooperación significa que los niveles locales y regionales alcanzan una posición de negociación más igualitaria en relación con el contexto nacional (Allen, 2012). Al mismo tiempo, Veggeland (2000) sugiere que está en los Estados y municipios decidir hasta qué punto aceptarán la creciente responsabilidad y autonomía específica en términos del contrato.

Una característica importante del régimen ambiental México-Estados Unidos es que el sistema de gobernanza es asimétrico (Ibáñez, 2008); esto, debido a que las regiones alcanzan diferentes grados de soberanía en los acuerdos o en los contratos específicos. Lo anterior se da principalmente porque los recursos políticos, económicos y administrativos entre una región o ciudad fronteriza son diferentes y por ende constituyen las bases para la desigualdad de soberanía. Por ello, es preciso conocer cuál ha sido la efectividad del régimen ambiental México-Estado Unidos, y sus posibles alcances para mitigar el problema hídrico en la región fronteriza.

\section{Efectividad: la importancia de la política ambiental}

Una característica sobresaliente de la década de los setenta en adelante es la aparición de una clara y creciente preocupación pública acerca de los problemas ambientales a gran escala y el surgimiento de regímenes ambientales como un medio para atender estos problemas. Sin embargo, lo importante es conocer si un determinado régimen es capaz de resolver los problemas que motivaron a los actores a invertir tiempo y energía para crearlos (Levy et al., 1994).

Como punto de partida, es necesario comprender que los regímenes ambientales internacionales no producen resultados por sí mismos solo por el hecho de que sus integrantes acuerden trabajar juntos para atacar una problemática ambiental común. Para tener éxito, los regímenes ambientales tienen que depender de la voluntad y coincidir en los intereses de los países miembros para resolver un problema específico; pero también, y aún más importante, deben contar con los mecanismos apropiados para guiar las acciones de los agentes involucrados; es decir, la elaboración de leyes y compromisos administrativos a nivel local, nacional e internacional. En este sentido, la operación exitosa de los regímenes ambientales depende en gran medida de cómo sean creadas e implementadas sus políticas ambientales.

El régimen ambiental México-Estados Unidos es una construcción multilateral de leyes, reglas, directivas, acuerdos y procedimientos que son negociados por actores en campos específicos de la política. Esto significa que este régimen fue formado por la necesidad de 
una cooperación mutua para encontrar una solución a la problemática ambiental de la región fronteriza (Ibáñez, 2008).

De este modo, es posible dividir la integración de las directrices de este régimen de acuerdo a tres tareas. Primero, construir objetivos políticos y procedimientos; segundo, construir instituciones políticas; y tercero, desarrollar la habilidad para gobernar y aprobar medidas capaces de resolver problemas con implicaciones ambientales, así como otros asuntos políticos, económicos y socioculturales. De acuerdo con Young (1999), se incluiría a esta última tarea el argumento de que, para alcanzar la efectividad en un régimen ambiental, existen además otros dos elementos que deben ser considerados: la observancia de las políticas y la buena implementación de las políticas públicas.

Con respecto al régimen ambiental México-Estados Unidos, el hecho de que los Estados miembros tengan profundas diferencias en sus sistemas de gobierno, afecta de forma inevitable el modo en que abordan los problemas ambientales, y en especial del agua, dentro de la región fronteriza. En esencia, existen dos diferencias fundamentales entre ambos países que es preciso destacar. La primera tiene que ver con la forma en que cada país aborda y maneja los asuntos ambientales, ya sea desde un enfoque arriba-abajo (top-down) o abajoarriba (bottom-up). En segundo lugar, en relación con la postura y disposición de cada país para negociar y cooperar, es decir, qué quiere obtener cada uno.

En México, el dominio federal sobre la toma de decisiones (o un enfoque político de topdown) en muchos asuntos concernientes a los recursos naturales, aísla la toma de decisiones de política exterior de la influencia subnacional. En otras palabras, la influencia de intereses locales y estatales figura muy poco al determinar la posición del país en el momento de negociar los acuerdos. Sin embargo, esto no significa que los intereses internos no estén expresados o que afecten la política bilateral. Significa que el gobierno procede con gran discreción en relación con los intereses internos y puede actuar independientemente de ellos al formar acuerdos bilaterales sobre agua o cualquier otro tema.

Por otra parte, la descentralización política en Estados Unidos otorga a los estados fronterizos y los grupos de interés un papel influyente en la toma de decisiones, así como también en la creación de las políticas públicas (este enfoque político es comúnmente conocido como bottom-up). El agua, por ejemplo, representa un interés económico fundamental en la frontera y es tan importante que obliga a los estados y municipios a movilizar sus intereses para influir en las relaciones bilaterales en este ámbito. En la mayoría de los casos, la diplomacia interna ha sido un prerrequisito para la diplomacia internacional; al mismo tiempo, el sistema político de Estados Unidos ofrece a los estados y a otros actores interesados un poder sustancial sobre los asuntos ambientales. En este sentido, los estados y municipios fronterizos de la parte 
estadounidense tienen un efectivo sistema para actuar en conjunto e influir en los resultados de los acuerdos firmados con México.

Sin embargo, una de las diferencias más importantes al respecto, es el hecho de que México aún es vulnerable a la dominación de Estados Unidos dentro del marco del régimen, en especial en lo referente a asuntos bilaterales. Esta vulnerabilidad se debe a una serie de factores que actúan en conjunto, ya sean asuntos históricos, políticos, económicos e incluso raciales. Lo que es extraño y difícil de entender es la debilidad de México, a pesar de haber seguido estrategias de negociación y cooperación más profundas, enfatizando el uso de la ley internacional, el principio de distribución equitativa y la necesidad de los recursos naturales para mejorar sus posibilidades de concentración. En este sentido, pese a que desde la inclusión de México en el Acuerdo General sobre Aranceles y Comercio (GATT) en 1986, a su mayor participación en acuerdos internacionales y a que es catalogado como una economía emergente a nivel continental e internacional, aún permanece como un agente menor dentro de cualquier régimen que comparta con Estados Unidos. No obstante, el sistema de gobernanza ambiental permite, bajo una perspectiva neoliberal, la cooperación y no solo la coordinación de acciones para solucionar las problemáticas ambientales fronterizas.

En concordancia con lo anterior, la posición y disposición de Estados Unidos para negociar y cooperar dentro del escenario bilateral, ha estado siempre marcada por el apoyo incondicional de Washington a los estados fronterizos y viceversa (Rabassa, 2008; Konisky y Woods, 2010). Esto se ha reflejado en la forma en que las negociaciones y estrategias de cooperación tienen lugar, es decir, con completa consideración de las necesidades de ambas partes. Esta fuerte unión ha conducido a que Estados Unidos obtenga mejores resultados durante y después de las negociaciones de los acuerdos bilaterales en materia ambiental con México (Mumme, 2015). Es entendible que Estados Unidos se vea asimismo mejor posicionado que México dentro del régimen, debido a su potencial económico y político. Esto explica por qué Estados Unidos no se ha preocupado de utilizar mejores estrategias para negociar y cooperar con México. En su lugar ha elegido utilizar soluciones más técnicas y focalizadas en la parte de su frontera en vez de operar con criterios rigurosos (Olive, 2015).

Dentro de los principales problemas medioambientales que enfrenta toda la franja fronteriza entre México y Estados Unidos, la coordinación de los proyectos de suministro y tratamiento del recurso agua es sin duda la acción con mejores resultados dentro del régimen. De acuerdo con G. Frisvold y M. Caswell:

el $90 \%$ de los 12 millones de personas que viven dentro de los $100 \mathrm{~km}$ de la frontera México-Estados Unidos están agrupados en 14 pares de ciudades hermanas, lo que provoca que el control transfronterizo de la contaminación y el 
tratamiento del agua a lo largo de la frontera sea complicado, generando disparidades en los ingresos entre los dos países. (2000, p. 101)

\section{Tratamiento del recurso agua dentro del régimen ambiental México-Estados Unidos}

A principios de la década de los noventa, México realizó un gran esfuerzo por implementar un sistema de descentralización política y administrativa a lo largo del país (Arcudia, 2012). Estos y otros avances administrativos en el campo de la política pública en México ayudaron al régimen a avanzar hacia una mejor posición para enfrentar los problemas ambientales y en especial el del agua. ${ }^{14}$ No obstante, existe una larga lista de pendientes que el régimen tiene que abordar; uno de estos es su estructura. Tal como es en la actualidad, representa el máximo esfuerzo hecho por ambos gobiernos para resolver problemas ambientales y demandas en la región fronteriza. Sin embargo, ¿ha sido el régimen capaz de resolver los principales problemas para los cuales fue creado? En primer lugar, se podría argumentar que a pesar de que la estructura se ha movido lento desde un enfoque jerárquico o de top-down hacia una tendencia más interdependiente o incluyente, los esfuerzos no han sido suficientes para atender los grandes problemas ambientales que aún sufre esta región.

En este sentido, el régimen ha transitado de los contenidos cerrados y tendenciosos de los Tratados de $1906^{15}$ y $1944^{16}$ y de la CILA, a los mandatos y acciones más amplias e incluyentes como los del Acuerdo de La Paz, Frontera XXI y COCEF-BDAN, a través del

14 En 1994 se creó la Secretaría de Medio Ambiente, Recursos Naturales y Pesca (Semarnap), que se encargaría de atender en forma integral la conservación y el aprovechamiento de los recursos naturales del país, bajo la perspectiva del desarrollo sustentable. Para el desarrollo de sus funciones, la Semarnap se apoyaría en el Instituto Nacional de Ecología (INE) y en la Procuraduría Federal de Protección al Ambiente. A finales del año 2000, la Semarnap fue reestructurada, separándose el sector Pesca de la institución. Esto implicó el cambio de su nombre por Secretaria de Medio Ambiente y Recursos Naturales (Semarnat).

15 La Convención de 1906 es el primer tratado bilateral enfocado en el uso compartido de las aguas superficiales, concernientes a la parte alta del Río Grande. En esta Convención se prepara la distribución sobre las aguas del Río Grande entre México y Estados Unidos (SRE, 2017).

16 El Tratado de Aguas de 1944 es el mayor acuerdo de distribución de agua entre las dos naciones. Además, se autorizó la construcción, operación y mantenimiento de presas para que cada país recibiera aproximadamente la misma cantidad de agua (SRE, 2017). 
Programa Frontera 2020. ${ }^{17}$ Lo anterior sugiere que existe un cambio hacia un enfoque más descentralizado y participativo, en vez de uno con características de bottom-up. ${ }^{18}$

Para el caso de la gestión del agua, "ningún otro factor ha tenido mayor influencia en el desarrollo de la región fronteriza entre México y Estados Unidos, que el agua" (Smerdon, 1982, p. 907). Los desarrollos municipales, industriales y agrícolas son, en gran medida, dependientes de los recursos acuíferos superficiales y subterráneos, al punto de que toda el agua de la superficie está apropiada y las aguas subterráneas están siendo extraídas (Alfie, 2005). Estas situaciones han repercutido, en cierto modo, en las relaciones bilaterales entre ambos países. La naturaleza esencial de este recurso, su escasez y degradación, que son evidentes en el área, hacen posible anticipar tensiones y conflictos en la medida en que los problemas de agua lleguen a ser más agudos.

Bajo este orden de ideas, la situación que se vive en la mayoría de las regiones fronterizas en la que se comparte el recurso agua es en sí misma una fuente de conflicto, en el sentido de que la dependencia asimétrica existente entre los habitantes de las riberas altas y bajas detona tensiones políticas, medioambientales y sociales. En el caso del régimen motivo de este artículo, también se presenta una asimetría de poder, en la que México (país emergente) se enfrenta al poder estadounidense. Así, aquellos ribereños bajos son más vulnerables que los que se ubican por encima, pudiendo recibir un acceso discriminatorio a los recursos acuíferos (Baechler, 1998). Además, los problemas de abastecimiento de agua también están relacionados a la distribución de bienes públicos y normalmente afectan la soberanía e integridad nacional. Mientras que los problemas de contaminación de agua representan una emulación sobre un bien público indivisible que afecta los niveles de responsabilidades políticas y costos económicos. En este sentido, el curso geográfico de los ríos desempeña un papel importante en acentuar el problema de suministro y contaminación del agua.

Para el caso de la región fronteriza México-Estados Unidos, el ribereño alto (Estados Unidos), al menos en el río Colorado, cuenta con mejores y eficientes sistemas tecnológicos, así como también con un poder adquisitivo mayor que el de su contraparte mexicana, por lo que el balance de poder se inclina hacia el ribereño estadounidense. De este modo, Estados Unidos es capaz de discriminar de forma precipitada a México (como el ribereño bajo), regulando las corrientes transfronterizas y la calidad del agua.

17 Este programa binacional se enfoca en mejorar la calidad del aire, suministrar agua potable segura, reducir el riesgo de la exposición a desechos peligrosos y garantizar la preparación ante emergencias a lo largo de la frontera México-Estados Unidos.

18 Para un análisis de la línea del tiempo de los diferentes tratados y convenciones firmados entre México y Estados Unidos en materia del recurso agua, ver la siguiente liga electrónica: https://cila.sre.gob.mx/cilanorte/index.php/avisos/127-tratconv 
Lo anterior propone que, a lo largo de la frontera, los problemas ambientales y de agua representan un foco de alerta para ambos países y deben ser priorizados en la agenda del régimen ambiental México-Estados Unidos. En este sentido, es posible identificar cuatro grandes problemas relacionados con los recursos acuíferos en la frontera entre México y Estados Unidos. El primero se refiere al abastecimiento equitativo del agua, en relación con los acuerdos existentes. El segundo tiene que ver con la escasez actual y futura del recurso; el tercero está relacionado con la contaminación de las aguas y, finalmente, el cuarto dice relación con las aguas freáticas a lo largo de la zona fronteriza. Es importante resaltar que la mayoría de los problemas mencionados dependen de otras presiones externas, tales como el crecimiento poblacional, las condiciones climáticas y geográficas, junto con el ambiente político y socioeconómico, que también son factores determinantes de los problemas de agua transfronterizos.A continuación se analizan los principales problemas identificados en relación con el tratamiento del agua, en los que el régimen debe concentrarse.

\section{Distribución equitativa del agua}

En relación con la distribución del agua entre México y Estados Unidos, esta se regula por dos tratados internacionales: el de 1906 y el de 1944. El Tratado de 1906 establece que anualmente el gobierno de Estados Unidos debe otorgar a México un volumen de 74 millones de metros cúbicos de aguas del río Bravo para uso agrícola en el valle de Juárez. De acuerdo con este tratado, el agua deberá ser entregada en la bocatoma de la Acequia Madre o viejo canal mexicano, al noroeste de Ciudad Juárez, proveniente de las presas Elephant Butte y Caballo, en Nuevo México, de acuerdo a una tabla de volúmenes mensuales (Bustillos, 2004; SRE, 2017). Asimismo, el tratado establece que en caso de extrema sequía, el volumen se reducirá en la misma proporción que sufran las tierras en Estados Unidos. La entrega del agua no implica que Estados Unidos reconozca derechos por parte de México ni otorgue ningún fundamento legal para reclamaciones futuras (SRE, 2017).

Por otro lado, con base en el Artículo 4, apartado B del Tratado de 1944, se establece la asignación de volúmenes de agua de los cauces de los ríos que marcan la frontera, el Bravo y el Colorado. Para el río Bravo el tratado define los volúmenes entre Fort Quitman, Texas y su desembocadura en el Golfo de México; y para el río Colorado, en Mexicali. El tratado otorga a Estados Unidos, como parte de la distribución del río Bravo, la totalidad de las aguas procedentes de los ríos Pecos y Devils, del manantial Goodenough y de los arroyos Alamito, Terlingua, San Felipe y Pinto; así como la mitad del caudal del río abajo de la presa Falcón. Asimismo, se le asigna el derecho a recibir una tercera parte del agua procedente de los ríos Conchos, San Diego, San Rodrigo, Escondido y del arroyo de Las Vacas, siempre que esta tercera parte no sea inferior a 431,7 millones de metros cúbicos al año, en promedio, en ciclos de cinco años (ver Tabla N 1) (DEC, 2002; SRE, 2017). 
Por otra parte, el tratado asigna a México, como parte de la distribución del río Bravo, el derecho sobre la totalidad de las aguas de los ríos San Juan y Álamo, así como la mitad del caudal río abajo de las presas Amistad y Falcón, y dos terceras partes del líquido que llega al cauce principal procedente de los ríos Conchos, San Diego, San Rodrigo, Escondido y Salado, así como del arroyo de Las Vacas, siempre que se satisfaga el derecho de Estados Unidos a recibir al menos 431,72 millones de metros cúbicos anuales mencionados anteriormente (2.158 millones de metros cúbicos quinquenales). En caso de que haya faltantes por "extrema sequía", se repondrán en el ciclo siguiente, salvo en caso de lluvias abundantes que llenan las presas (ciclones, huracanes), con lo cual se inicia un nuevo ciclo (Bustillos, 2004; DEC, 2002; SRE, 2017).

Cada país también tiene derecho a recibir la mitad de los restantes caudales del río no asignados de otro modo, incluyendo las aportaciones de los tributarios no aforados entre Fort Quitman y Presa Falcón. El artículo 10 establece que México tiene derecho a recibir el 10\% del volumen del río Colorado (1.850,23 millones de metros cúbicos de agua anuales), más 246 millones adicionales cuando existan excedentes, de manera que el total no exceda los 2.096 millones. Además, el recibir este excedente no crea derechos por parte de México (Bustillos, 2004; DEC, 2002; SRE, 2017).

TABLA N 1

Distribución de agua fronteriza según convención o tratado (millones de metros cúbicos)

\begin{tabular}{|c|c|c|}
\hline & Convención 1906 & Tratado 1944 \\
\hline \multicolumn{3}{|l|}{ Río Bravo } \\
\hline México & 74,0 & \\
\hline Estados Unidos & & 431,72 \\
\hline \multicolumn{3}{|l|}{ Río Colorado } \\
\hline México & & 1850.2 \\
\hline Estado Unidos & & \\
\hline
\end{tabular}

Fuente: Elaboración propia con datos de SRE (2017)

En caso de renegociar la distribución de las aguas internacionales, los participantes en el régimen deben desempeñar un papel decisivo. Es importante mencionar que cuando se firmó el Tratado de 1944, la CILA solo manejaba situaciones concernientes a problemas fronterizos. Sin embargo, la participación activa de esta en la negociación con los representantes de ambos países, tuvo un efecto definitivo en la asignación de las aguas compartidas. A pesar de esta situación, la CILA es ahora un miembro importante en el régimen ambiental México-Estados Unidos, el cual en principio está mejor informado, es más consciente de los problemas y cuenta con un mayor conocimiento de los asuntos de agua 
y de los problemas que los rodean. Sin embargo, hasta ahora no ha sido posible modificar los porcentajes de distribución del agua a favor de México.

\section{Abastecimiento de agua}

El agua es uno de los elementos fundamentales para el crecimiento y desarrollo de la franja fronteriza; no obstante, el problema de su escasez es un asunto de inmadurez en la conciencia ambiental de la comunidad, o un problema que tiene sus orígenes en los procesos de elaboración e implementación de políticas públicas. Esta situación es sin duda un problema latente que, de no ser atendido, tendrá serias consecuencias para la población, para el crecimiento económico y para el medio ambiente fronterizo. Sin embargo, cualquiera que sea la fuente de esta situación, es necesario gestionar de manera eficiente el agua y comenzar a satisfacer las demandas eficazmente. En este contexto, la CILA, la COCEF y el resto de las dependencias nacionales tienen una responsabilidad directa, tal como está establecido en los documentos que los crearon.

A pesar de que algunos atributos han sido ya incluidos dentro de las obligaciones de los miembros del régimen, existen algunos otros roles que deben ser revisados y reajustados a las constantes y crecientes demandas de agua. Por ejemplo, es necesario adaptar aquellas funciones que corresponden a los gobiernos de México y Estados Unidos para emprender trabajos públicos que están relacionados con la conservación del agua, tales como presas, canales, dársenas, entre otros. A pesar de que estos trabajos de conservación son centrales en el régimen, son también sin duda necesarias para mantener el costo de agua relativamente bajo. Sin embargo, si no son atendidos, la región fronteriza enfrentará en el corto plazo situaciones en las que el costo del recurso será tan alto que el trabajo de conservación no será sostenible.

Por ejemplo, actualmente cerca de 20 millones de personas en esta región hacen uso del agua cada día. En Estados Unidos, el número total de unidades de casas ocupadas con agua entubada en los años sesenta era de $90 \%$ (Gráfico $\mathrm{N}^{\circ}$ 1); para la década de los noventa, $99 \%$ de estas casas ya tenía agua entubada (United States Census Bureau, 2017). Comparado con México, en la década de los sesenta, cerca del $41 \%$ de las casas tenía agua entubada y a pesar de que hubo un importante crecimiento del lado mexicano, se alcanzó el $90 \%$ de este indicador en los años noventa (INEGI, 2017). 


\section{GRÁFICO No 1}

Porcentaje de casas ocupadas con agua entubada en estados fronterizos

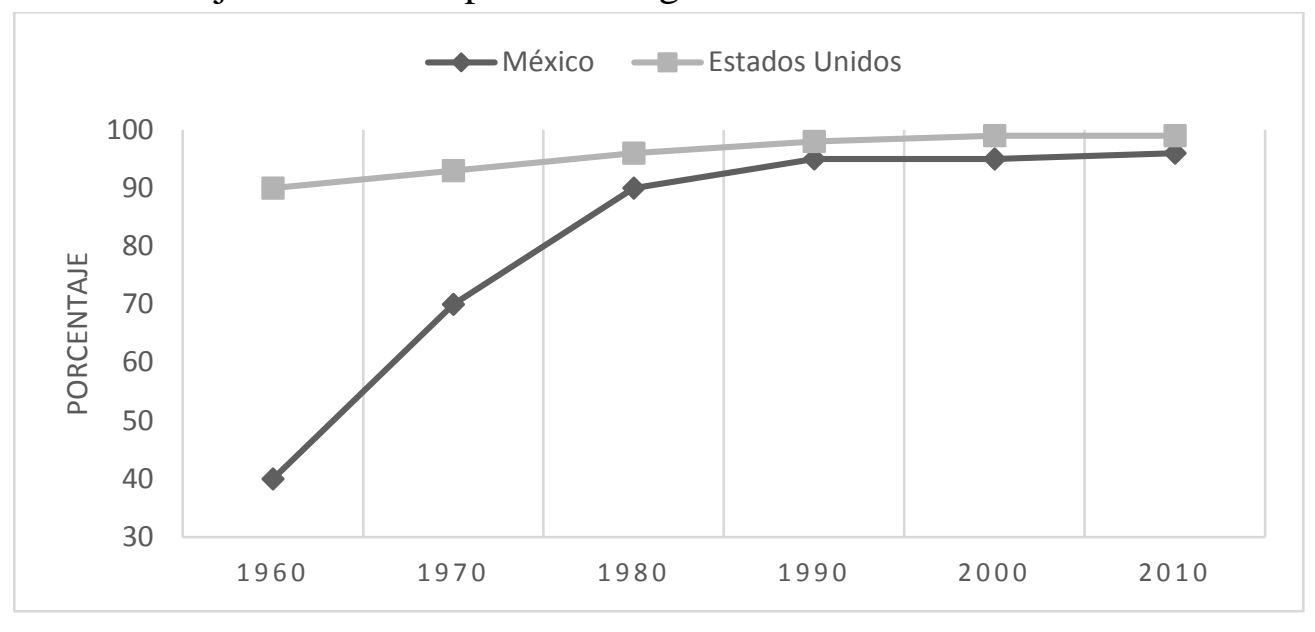

Fuente: Elaboración propia con datos de INEGI (2017) y United States Census Bureau (2017).

Lo anterior refleja la presión económica y social que recibe el recurso agua en la zona fronteriza, lo que implica que se requiere una mejor coordinación entre los integrantes del régimen ambiental, a fin de utilizar sustentablemente el recurso agua. Sin embargo, otro de los problemas centrales es sin duda mejorar la calidad del agua.

\section{Calidad del agua}

La deficiente calidad del agua en los ríos fronterizos es una consecuencia de los procesos de sustracción de agua que incluyen, entre otros, los proyectos de infraestructura, la sobreexplotación de los recursos freáticos y las descargas de desechos humanos y tóxicos, los cuales han ido dañando el ecosistema de esta zona (Rascón, 2016). Aunado a esto, desde la década de los noventa la región fronteriza, particularmente del lado mexicano (Tabla $\mathrm{N}^{\circ}$ 2), experimentó un crecimiento acelerado de la industria manufacturera, en especial de la maquiladora, cuyos efectos secundarios han sido la mayor fuente de Demanda Biológica de Oxígeno (DBO) ${ }^{19}$ En este sentido, existe evidencia empírica (Rascón, 2016; González y Sánchez, 2013; CERCA, 2009; Bustillos, 2004; Lemus, 1995) que demuestra que el mayor número de plantas maquiladoras instaladas en la región ha repercutido en el deterioro de la calidad del agua. Esta situación se debe principalmente a que las aguas recogen las descargas municipales, desechos agrícolas y algunos otros tipos de afluentes industriales (maquiladora).

19 Se define como D.B.O. de un líquido la cantidad de oxígeno que los microorganismos, especialmente bacterias, hongos y plancton, consumen durante la degradación de las sustancias orgánicas contenidas en la muestra. Se expresa en mg/l. Es un parámetro indispensable cuando se necesita determinar el estado o la calidad del agua de ríos, lagos, lagunas o efluentes. 


\section{TABLA $\mathrm{N}^{\circ} 2$}

Número de maquiladoras instaladas en los estados fronterizos mexicanos

\begin{tabular}{cc}
\hline Año & $\begin{array}{c}\text { Número de } \\
\text { maquiladoras }\end{array}$ \\
\hline 1975 & 418 \\
1980 & 544 \\
1990 & 1.464 \\
2014 & 3.068 \\
\hline
\end{tabular}

Fuente: Elaboración propia con datos de Mungaray (1998) e INEGI (2017).

El problema de la contaminación de las aguas superficiales está causando pérdidas irreparables al medio ambiente a lo largo de la frontera compartida. Sin duda, un factor de la proliferación de esta problemática es la forma ineficiente en que el régimen ha manejado las aguas fronterizas por más de 50 años. El hecho de que no existan reglas, ni normas bien definidas para imputar las responsabilidades jurídicas de un país a otro por la contaminación de las aguas internacionales, ha sido en realidad un gran obstáculo para alcanzar soluciones satisfactorias. El Tratado de 1944 no especifica dentro de su contenido las responsabilidades por la contaminación de las aguas. Solo en el artículo 17 señala que "el uso del cauce de los ríos internacionales para la descarga de aguas de avenida o de otras excedentes será libre y sin limitación para los dos países y ninguno de ellos podrá presentar reclamaciones al otro por daños causados por dicho uso" (SRE, 2017).

Lo anterior refleja que deben hacerse modificaciones profundas a los tratados que rigen el régimen ambiental México-Estados Unidos, y otorgar mayor empoderamiento a los actores del mismo, con el objeto de relacionar el uso y conservación de las aguas fronterizas para propósitos domésticos, económicos y agrícolas, junto con fortalecer un sistema de sanciones efectivas para quienes contaminan.

\section{Asuntos sobre aguas freáticas}

Por último, las aguas freáticas en la frontera han sido consideradas como una de las preocupaciones más importantes en las que el régimen debería enfocar sus esfuerzos, debido a sus implicaciones en el desarrollo a lo largo de los límites y áreas inmediatas de la frontera. De acuerdo con G. Hatch y V. Ibarra (2015), la sobreexplotación de los recursos freáticos ha originado daños irreparables, como el aumento de la salinidad del agua y el hundimiento del suelo en algunas zonas importantes de la frontera norte de México. En este sentido, autores como C. Sepúlveda y A. Utton (1984) sugirieron en la década de 1980 que el Tratado de 1944 debía ser revisado para considerar las aguas freáticas como aguas fronterizas, a fin de 
que las aguas superficiales y freáticas no se interpretaran de manera separada. La revisión que ellos sugerían debía incluir una ampliación a la jurisdicción de la CILA a todas las aguas compartidas en la superficie y en el subsuelo, exceptuando las aguas marítimas. En este sentido, Sepúlveda y Utton (1984) también propusieron la puesta en marcha de un nuevo tratado, el cual gobernaría la adjudicación de aguas de manera equitativa. Pese a que la Minuta 242 de la CILA incluyó en 1973 (CILA, 2017) que el acuerdo fuera de esta manera, E. Smerdon (1982) y F. Oyarzabal (1982) consideraron que esto es solo posible si ciertas condiciones son practicadas. Algunas de ellas son, por ejemplo, la localización exacta de los acuíferos y su calidad, el uso que esta agua debe tener cuando sea ubicada, el riesgo de contaminación y la forma en que el recurso debe ser distribuido entre México y Estados Unidos. Actualmente, ni los gobiernos de ambos países ni los programas propuestos en Frontera 2020 han hecho algo para resolver esta situación.

Por último, la CILA como institución medular de régimen ambiental también enfrenta desafíos futuros. En este sentido, por cuestiones de soberanía nacional, la institución está totalmente controlada por los gobiernos centrales, situación que se deriva, desde sus orígenes, de la delimitación de las fronteras y la repartición de las aguas del río Colorado. Sin embargo, la CILA en los últimos 60 años ha dedicado más tiempo a la creación y operación de infraestructura relacionada con servicios públicos correspondiente a los gobiernos locales, tales como el suministro de agua para las ciudades y el saneamiento de aguas urbanas con participación muy limitada, pero creciente, de los gobiernos estatales y locales. En la actualidad, la CILA trabaja en la localización de nuevas fuentes de agua para poder dotar la creciente demanda del líquido, en un escenario de escasez del líquido en la región (Abita, 2018). Si bien la CILA se adapta a las condiciones de la región, las condiciones cambiantes del entorno no han logrado un diseño nuevo de una institución que responda a la realidad actual, que implicaría la apertura formal a actores locales y regionales sin que estén subordinados a los gobiernos centrales, sino que sean parte de esta estructura como asociados y no como observadores. La tarea pendiente que queda es la actualización de la CILA, en la que incluya de manera formal y constante a los actores del entorno inmediato de las cuencas que administran.

\section{Conclusión}

Como se ha podido observar, muchos factores contribuyen al carácter de niveles múltiples de las políticas ambientales y forman una dimensión decisiva de la cooperación ambiental internacional. En primer lugar, los asuntos ambientales, por su misma naturaleza, desafían la lógica de las divisiones políticas y territoriales aceptadas en y entre naciones. La degradación 
ambiental regional pone en riesgo a todos los individuos de una sociedad, a las comunidades locales, a los gobiernos centrales y a las organizaciones internacionales.

En segundo lugar, la lucha contra la degradación ambiental, la escasez y la contaminación de agua sobre la frontera México y Estados Unidos requiere de la acción cooperativa binacional, en la que las políticas ambientales locales y regionales deben desempeñar un papel esencial. La internacionalización de las políticas ambientales también significa que las entidades locales y regionales están ejerciendo un papel cada vez más importante en la elaboración e implementación de los acuerdos.

Tercero, la proliferación de acuerdos y programas ambientales entre México y Estados Unidos fortalece la imagen de progreso sobre la cooperación ambiental que se tiene fuera de los confines nacionales y regionales. Sin embargo, la mayoría de estos acuerdos enfrentan serias imperfecciones de implementación, las cuales se multiplican dados la creciente presión del tiempo y los reducidos periodos de implementación, lo que también se ve reflejado en la ineficiencia de dichos acuerdos para solucionar los problemas por los cuales fueron creados.

En este sentido, las arenas políticas nacionales y regionales cobran mayor peso y relevancia, incluso en donde los gobiernos centrales tienen el poder para actuar solos, puesto que la prudencia política y la situación medioambiental de la frontera demandan que estos no ignoren los intereses subnacionales y sectoriales, ya que los asuntos ambientales son en la actualidad parte del debate político mundial.

El régimen ambiental México-Estados Unidos es un caso de estudio único en el que los diferentes niveles de elaboración e implementación de políticas públicas convergen hacia fines comunes. Así, las políticas ambientales ejemplifican la creciente importancia de los actores subnacionales en las relaciones internacionales. La forma específica en que este régimen opera realza la voluntad de ambos países para manejar los delicados problemas ambientales en el área. Desde la creación de la CILA, la cual marcó el comienzo del régimen, las instituciones ambientales de la región fronteriza han realizado diferentes intentos para unir las habilidades de la comisión y reparar el mal uso de los recursos naturales en la zona. El Acuerdo de La Paz es el mejor ejemplo de estos esfuerzos, no solo por parte de los gobiernos de ambos países, sino también del Estado y los gobiernos locales y grupos de interés regionales que tuvieron la oportunidad, por primera vez, de participar en la creación de soluciones a sus problemas. Asimismo, después de la puesta en marcha del TLCAN, más instituciones comenzaron a operar con el objetivo de apoyar los esfuerzos de la CILA y el Acuerdo de La Paz. No obstante, hasta ahora, las instituciones que participan en la dinámica del régimen no han mostrado mejorías en los cuatro principales problemas de agua en la frontera. 
Podría argumentarse que es muy pronto para visualizar alguna clase de efecto positivo; sin embargo, mientras más miembros participen, ya sea en la elaboración de políticas públicas y proyectos, como en su implementación, será más difícil que exista cooperación entre ambas partes. Además, la historia de conflictos entre ambos países por problemas en la región fronteriza ha sido similar a un campo de batalla desde hace 150 años.

Otro factor se podría atribuir a la poca efectividad del COCEF y el BDAN en la dinámica del régimen. Pese a que cuentan con la infraestructura necesaria y con suficientes recursos para manejar los problemas ambientales en la región, la inclusión de estas instituciones crea tensión, no solo en los gobiernos federales, estatales y locales, sino también con la CILA. Esto no quiere decir que la COCEF y el BDAN estén fuera de lugar para afrontar los problemas ambientales fronterizos, pero debido a la política y a las amplias facultades de las que ahora gozan, amenazan y limitan el campo de acción de otros, incluyendo a los gobiernos de los niveles estatales y locales, pese al fomento de la participación de niveles múltiples. No obstante, la COCEF y el BDAN tienen la habilidad de incluir sectores que estuvieron por completo excluidos del proceso de elaboración e implementación de políticas públicas. Y este hecho hace la diferencia entre la CILA y las instituciones creadas con y después del Acuerdo La Paz, en comparación con las instituciones del régimen posteriores al TLCAN. Es decir, existen riesgos en un sistema de niveles múltiples de gobernanza y, algunas veces, esto puede ser dañino para la dinámica del mismo régimen.

Por tanto, los niveles múltiples de gobernanza podrían ser analizados en dos formas diferentes: aquellos que favorecen la inclusión de varios actores o participantes en diferentes niveles de acción dentro de los procesos de elaboración e implementación políticas públicas; y aquellos que están en contra de este proceso de participación múltiple, argumentando que este solo contamina la comunicación entre los actores. La experiencia ha demostrado que pueden encontrarse esta clase de realidades, dependiendo del régimen y del contexto en el cual esté inmerso. Esto quiere decir que es posible hallar situaciones en donde los regímenes que involucran niveles múltiples, se desempeñan efectiva o inefectivamente; y otras, en las que las instituciones hegemónicas dominan el desempeño del régimen y arrojan buenos o malos resultados.

El hecho de que muchos actores localizados en diferentes niveles conformen el régimen ambiental México-Estados Unidos, muestra que es posible que existan situaciones conflictivas. Por ejemplo, el régimen tiene que resolver el ajuste de las estructuras gubernamentales para poder alcanzar enfoques coherentes de gobernanza y, al mismo tiempo, repartir responsabilidades, grados de autonomía para cada autor, para cada nivel y fortalecer los mecanismos de coordinación intergubernamental. Hasta ahora, el régimen no ha resuelto estos problemas internos administrativos. 
En conclusión, los problemas ambientales y los relacionados con el agua están aún más presentes en la región fronteriza y amenazan con empeorar en un futuro cercano. El abstencionismo y calidad del agua siguen siendo los principales asuntos dentro de las instituciones que conforman el régimen ambiental México-Estados Unidos. No obstante, este no ha sido capaz de arrojar soluciones más sustentables y efectivas para el manejo del agua. En este sentido, surgen cuestionamientos que deben ser resueltos en el corto-mediano plazo por todos los actores que integran el régimen ambiental: ¿cuántos años más necesita el régimen para que sean evidentes las mejoras en el medio ambiente y en la calidad de vida de la población que habita a lo largo de la región fronteriza? ¿Ha beneficiado la inclusión de COCEF y BDAN en la infraestructura del régimen, los procesos y dinámicas de implementación? ¿Podrán todos los integrantes del régimen ambiental México-Estados Unidos resolver los problemas relacionados con el agua en la frontera?

\section{Referencias}

Abita, L. F. (2018). Evolución institucional de la gestión de cuencas hidrográficas compartidas transfronterizas: cuencas bajas del río Colorado y del río Tijuana, y las cuencas de los ríos Miño y Limia (Tesis doctoral). Facultad de Ciencias Políticas y Sociología, Universidad Complutense de Madrid, Madrid.

Aguilar, L. (2014). Las dimensiones y los niveles de gobernanza. Cuadernos de Gobierno y Administración Pública, 1(1), 11-36.

Alfie, M. (2005). El agua en la frontera México-Estados Unidos: reto político-ambiental. Espacio Abierto Cuaderno Venezolano de Sociología, 14(2), 215-238.

Allen, L. (2012). The North American agreement on environmental cooperation: has it fulfilled its promises and potential? An empirical study of policy effectiveness. Colorado Journal of International Environmental Law and Policy, 3(1), 121-199.

Arcudia, C. E. (2012). La descentralización municipal en México. Nuevas relaciones intergubernamentales a partir de las reformas al Art. 115 de la Constitución. Nómadas. Revista Crítica de Ciencias Sociales y Jurídicas, Vol. Especial América Latina, 235-251. DOI: 10.5209/rev_NOMA.2012.41776

Baechler, G. (1998). Why environmental transformation causes violence: a synthesis. En Wilson Center (Ed.), Environmental Change and Security Program, Issue 4 (pp. 2444). Washington D. C.: The Woodrow Wilson Center. 
Berman, P. (1980). Thinking about programmed and adaptive implementation: matching strategies to situations. En H. Ingram y D. Mann (Eds.), Why Policies Succeed or Fail (pp. 205-227). California: Sage.

Braczyk, H. J. y Heindenreich, M. (2005). Regional governances structure in a globalized world. En P. N. Cooke, M. Heidenreich y H. J. Braczyk (Eds.), Regional Innovation Systems: The Role of Governance in a Globalized World (pp. 414-440). London: Routledge.

Bustillos, S. (2004). El agua en la frontera México-Estados Unidos. Araucaria, Revista Iberoamericana de Filosofía, Política y Humanidades, 6(11), 104-120.

Centro de Estudios Regionales y Comunicación Alternativa (CERCA) (2009). Impactos de la maquila en el medio ambiente de Ciudad Juárez. Nóesis. Revista de Ciencias Sociales y Humanidades, 18(36), 52-77.

Comisión Internacional de Límites y Aguas (CILA) (2017). Actas de la Comisión Internacional de Límites y Aguas entre México y Estados Unidos, Orden Cronológico. Recuperado de http://www.cila.gob.mx/actas/242.pdf

Conca, K. (1996). International regimes state authority and environmental transformation: the case of national parks and protected areas. Ocassional Paper No. 15, Harrison Program on the Future Global Agenda.

División de Economía y Comercio (DEC) (2002). Los problemas estructurales de la región hidrológica del Río Bravo y el cumplimiento del Tratado Internacional de Aguas entre México y Estados Unidos. Recuperado de http://www.diputados.gob.mx/sedia/sia/se/SIA-DEC-35-2002.pdf

Downs, G. y Mohr, L. (1976). Conceptual issues in the study of innovation. Administrative Science Quarterly, 21, 700-714.

Frisvold, G. y Caswell, M. (2000). Transboundary water management game-theoretic lessons for projects on the US-Mexico border. Agricultural Economics, 24(1), 101-111.

Gallagher, K. (2009). NAFTA and the environment: lessons from Mexico and beyond. En K. Gallagher, K. et al. (Eds.), The Future of North American Trade Policy: Lessons from NAFTA (pp. 61-69). Boston: Boston University. 
González, M. y Sánchez, V. (2013). Riesgo de contaminación del acuífero arroyo Alamar en Tijuana, Baja California. Región y Sociedad, 25(56), 103-126.

Haggard, S. y Simmons, B. (1987). Theories of international regimes. International Organization, 41(3), 491-517.

Harper, C. (1996). Environment and Society: Human Perspectives on Environmental Issues. New York: Prentice Hall.

Hasenclever, A., Mayer, P. y Rittberger, V. (1997). Theories of International Regimes. Cambridge: Cambridge University Press.

Hass, E. B. (1983). Words can hurt you; or who said to whom about regimes. En S. Krasner (Ed.), International Regimes (pp. 207-243). Nueva York: Cornell University Press.

Hatch, G. e Ibarra, V. (2015). Las aguas subterráneas transfronterizas México-Estados Unidos: importancia e invisibilidad dentro del contexto del TLCAN. América Latina Hoy, 69, 75-93.

Hoffmann, S. (1965). International systems and International law. En S. Hoffmann (Ed.), The State of War: Essays on the Theory and Practice of International Politics (pp. 87110). Nueva York: Praeger Publisher.

Ibáñez, O. (2008). Policy Change and Environmental Governance at the U.S.-Mexico Border: The Creation and Development of the Border Environment Cooperation Commission/North American Development Bank (Tesis doctoral). Colorado State University, Colorado.

INEGI (2017). Banco de indicadores. Recuperado de http://www.beta.inegi.org.mx/app/indicadores/?ag=15\&ind=3114005001\#

Jessop, B. (2000). Globalization and Governance. Roskilde: Universitet Forlaget.

Kaplan, M. (1964). System and Process in International Relations. Nueva York: Wiley.

Keohane, R. O. (1989). International Institutions and State Power. Londres: Westview Press.

Konisky, D. y Woods N. (2010). Exporting air pollution? Regulatory enforcement and environmental free riding in the United States. Political Research Quarterly, 63(4), 771-782. DOI: 10.1177/1065912909334429 
Kotow, V., Kux, S. y Nikitina, E. (1998). Ecology and Subsidiarity: The Emerging Role of Russia's Regions in Environmental Protection. Trabajo presentado en la 39th Annual Convention of International Studies Association, Minneapolis.

Krasner, S. (1983). Structural causes and regime consequences: regime as intervening variables. En S. Krasner (Ed.), International Regimes (pp. 1-22). Nueva York: Cornell University Press.

Lebel, L., Anderies, J. M., Campbell, B., Folke, C., Hatfield-Dodds, S., Hughes, T. P. y Wilson, J. (2006). Governance and the capacity to manage resilience in regional social-ecological systems. Ecology and Society, 11(1): 19. Recuperado de http://www.ecologyandsociety.org/vol11/iss1/art19/

Lemus, B. (1995). Industrial growth and water pollution on the Mexico-U.S. border: The case of Tijuana-San Diego. New Solutions: A Journal of Environmental and Occupational Health Policy, 5(1), 48-54. DOI: 10.2190/NS5.1.h

Levy, M. A., Young, O. y Zürn, M. (1994). The study of international regimes. International Institute for Applied Systems Analysis, Working Paper, 94-113. Recuperado de http://pure.iiasa.ac.at/id/eprint/4099/

Mumme, S. (2015). The evolution of natural resource conservation capacity on the U.S.Mexico Border: Bilateral and trilateral environmental agreements since La Paz. Review of Policy Research, Special Issue: Transboundary Natural Resource Governance in North America, 32(1), 19-39.

Mungaray, A. (1998). Maquiladoras y organización industrial en la frontera norte de México. Comercio Exterior, 48(4), 266-272.

Olive, A. (2015). Assessing intergovernmental institutions and transnational policy networks in North American resource management: concluding remarks. Review of Policy Research, 32(1), 163-169. DOI: 10.1111/ropr.12113

Oyarzabal, F. (1982). La calidad de las aguas del bajo río Bravo. Natural Resources Journal, $22(4), 925-937$.

Peña, S. (2011). Regímenes de planificación transfronteriza: México-Estados Unidos. Región y Sociedad, 23(50), 115-151. 
Pressman, L. y Wildavsky, A. (1973). Implementation. Berkeley: University of California Press.

Puchala, D. J. y Hopkins, R. (1983). International regimes: lessons from inductive analysis. En S. Krasner (Ed.), International Regimes (pp. 61-92). Nueva York: Cornell University Press.

Rabassa, M. (2008). Ambient Air Pollution and the Allocation of Environmental Enforcement Effort (Tesis doctoral). University of Illinois at Urbana-Champaign, Illinois.

Rascón, L. A. (2016). Calidad del agua en el río Bravo. Reunión Pública del Foro Ciudadano Región Ciudad Juárez [diapositivas de PowerPoint]. Recuperado de http://www.cila.gob.mx/foros/prpj171116.pdf

Saerbeck, B., Jörgensen, K. y Jänicke, M. (2017). Multi-level climate governance: The global system and selected sub-systems. Environmental Policy and Governance, 27(2), 105107. DOI: $10.1002 /$ eet. 1746

Scharpf, F. (1988). The joint-decision trap. Lessons from German federalism and European integration. Public Administration, 66(2), 239-78. DOI: 10.1111/j.14679299.1988.tb00694.x

Secretaría de Relaciones Exteriores (SRE) (2017). La CILA y los tratados y convenciones entre México y Estados Unidos en materia de límites y distribución de aguas de ríos internacionales. Recuperado de http://www.gob.mx/sre/acciones-y-programas/lacila-y-los-tratados-y-convenciones-entre-mexico-y-estados-unidos-en-materia-delimites-y-distribucion-de-aguas-de-rios-internacionales

Sepúlveda, C. y Utton, A. (Eds.) (1984). The U.S.-Mexico Border Region: Anticipating Resources Needs and Issues to the Year 2000. Texas: Texas Western Pres.

Smerdon, E. (1982). Water-Its role from now to the year 2000. Natural Resources Journal, 22(4), 907-914.

Stoker, G, (1998). Governance as theory: five propositions. International Social Science Journal, 50(155), 17-28.

UNESCO (2017), Education, Concept of Governance. Recuperado de http://www.unesco.org/new/en/education/themes/strengthening-educationsystems/quality-framework/technical-notes/concept-of-governance/ 
United States Census Bureau (2017). Housing Topics. Recuperado de https://www.census.gov/housing/

Veggeland, N. (2000). Neo-Regionalism: Planning for Devolution, Democracy and Development. Trabajo presentado en la IX Regional Studies Association Conference, Provence, Francia.

Vogler. J. (1995). The Global Commons: A Regime Analysis. Chichester: John Wiley and Sons Ltd.

Wale, A. (1992). The New Politics of Pollution. Manchester: Manchester University Press.

Wurzel, R., Zito, A. y Jordan, A. (2013). Environmental Governance in Europe: A Comparative Analysis of the Use of New Environmental Policy Instruments. Cheltenham: Edward Elgar.

Young, O. (1980). International regimes: problems of concept formation. World Politics, 32(3), 331-356. DOI: 10.2307/2010108

Young, O. (1989). International Cooperation: Building Regimes for Natural Resources and the Environment. Nueva York: Cornell University Press.

Young, O. (1997). Rights, rules and resources in world affairs. En O. Young (Ed.), Global Governance, Drawing Insights from the Environmental Experience (pp. 1-23). Massachusetts: MIT Press.

Young, O. (1999). Governance and World Affairs. Ithaca: Cornell University Press.

Cómo citar este artículo: Lascurain, F. (2018). Teoría de regímenes internacionales: el caso del recurso agua en el régimen ambiental México-Estados Unidos. Si Somos Americanos. Revista de Estudios Transfronterizos, 18(2), 128-158. 